\title{
Study Regarding the Leadership Styles Practiced in Catalan SMEs during the COVID-19 Pandemic
}

\author{
Laurențiu MIHAI \\ University of Craiova, Craiova, Romania \\ mihai.laurentiu09@gmail.com
}

\begin{abstract}
Received date:5 November 2020; Accepted date:7 June 2021; Published date: 8 September 2021
Academic Editor: NEGOITA Olivia Doina

Copyright (C) 2021. Laurențiu MIHAI. Distributed under Creative Commons Attribution 4.0

International CC-BY 4.0
\end{abstract}

\begin{abstract}
This paper's aim is to study the leadership styles practiced in Catalan SMEs during the COVID19 pandemic. The research focuses on three leadership styles (autocratic/transactional, democratic/transformational and laissez-faire/liberal) and how these styles are influenced by Hofeste's cultural dimension and other variables such as the SMEs' maturity level and the respondents' gender. Moreover, our paper studies the impact of the COVID-19 pandemic upon the Catalan business environment, discussing the government restrictions and aid measures. The research has been conducted in an empirical way, on a sample of 164 SMEs from Catalonia, Spain. Our results have shown that most of the respondents from this sample employ a democratic/ transformational leadership style and this style is influenced in a direct and positive way by the company's maturity and, at the same time, we found no significant correlation between the leadership style and the respondents' gender.
\end{abstract}

Keywords: leadership, COVID-19 pandemic, SME, Catalonia, management

\section{Introduction}

If leadership is a function, it must be considered an indispensable part of management, whose existence depends on a series of skills that form the leadership style of that person. Leadership is one of the concepts on which no consensus has been reached. As Stogdill (1974) states, the number of definitions of leadership is equal to the number of people who have tried to define it; however, many of these definitions take into account the "influence" factor.

Nowadays, the economic environment has become more dynamic and has led organizations to find new ways to cope with the changes they are undergoing. In such an environment, in order for organizations to be successful and survive, it is necessary for

Cite this Article as: Laurențiu MIHAI (2021)," Study Regarding the Leadership Styles Practiced in Catalan SMEs during the COVID-19 Pandemic" Journal of EU Research in Business, Vol. 2021 (2021), Article ID 414966, DOI: $10.5171 / 2021.414966$ 
them to be concerned with flexibility, dynamism and evolution, constantly avoiding stagnation.

Van Wart (2012) mentions that researchers need to develop an integral leadership model that combines transactional and transformational elements and, at the same time, takes into account the public context and different situational variables.

Leadership experts say that this concept is one on which the success or failure of an organization depends (Bennis, 2007; Burlea-Schiopoiu and Remme, 2017). Both researchers and practitioners recognize leadership as a major element that affects organizational performance (Bass, 2008; Rowe et al., 2005). They concluded that effective leadership helps increase organizational performance and facilitates the achievement of goals (Gordon and Yukl, 2004). The negative effects of inefficient leadership on organizational performance and employee attitudes confirm the importance and significance of effective leadership.

A large number of leadership theories have been developed in the last decades of the last century, stating that many of the styles proposed by these theories are similar, with certain characteristics being encountered in several leadership styles, which can lead to confusion among the leaders in the international business environment.

Hussain and Hassan (2016) consider that researchers need to develop an integral leadership model that combines transactional and transformational elements and, at the same time, takes into account the public context and different situational variables.

Most recent studies regarding leadership styles analyse this concept in a large company context (Peris-Ortiz et al., 2012; Quinta et al., 2015; Alonso-Almeida et al., 2015; Tintore, 2019) or in public institutions (Ricard et al., 2017), the literature lacking consistent studies regarding the leadership styles of small and medium enterprises' owner-managers (Burlea-Schiopoiu and Idowu, 2016).
This article aims to identify the dominant leadership style of SME's owner-managers from Catalonia, Spain, and to analyse how these styles are influenced by different variables, such as Hofstede's cultural dimensions, the company's level of maturity and the leaders' gender. At the same time, we could not ignore the current problems that the SMEs are facing because of the COVID-19 pandemic and we tried to understand how this crisis has affected our respondents' businesses.

This research is an extension of the authors' previous doctoral research, which focused on leadership styles of SME ownermanagers from Romania and the Netherlands. We have chosen Spain because, from a cultural point of view, it has both differences and similarities with Romania and the Netherlands, being somewhere between the two countries that were initially studied (Burlea-Schiopoiu and Mihai, 2019). Thus, Spain has a high distance from power, but significantly less than in Romania, with an average index of individuality, but with slight inclinations towards collectivism, a moderately feminine culture (aspect where it resembles Romania and in a smaller measure with the Netherlands), with a low degree of uncertainty tolerance. Specifically, we have focused our research on Catalonia, since it is one of Spain's most economically developed regions, with a strong entrepreneurial culture and a healthy SME environment.

In order to fulfil our research objectives, we tried to answer the following research questions:

Research question 1: Which is the dominant leadership style practiced by SME ownersmanagers from Catalonia, Spain?

Research question 2: Is there a significant correlation between the company's maturity and the owner-manager's leadership style?

Research question 3: Is there a significant correlation between the owner-managers' gender and their leadership style? 
Research question 4: How did the COVID-19 pandemic affect the respondents' business?

\section{Literature Review}

Research regarding leadership sometimes struggles with many different constructs.

The researchers are using concepts such as "leadership styles", "leadership models", "management styles" or "leadership theories" in order to study leadership from different perspectives (Quinta et al., 2015). Several researchers have studied the influence of different leadership styles on individual and organizational performance (Patiar and Mia, 2008; Burlea-Schiopoiu and Rainey, 2013; Quinta et al., 2015). The studies were based on the assumption that a manager's leadership style has a significant impact on the employees' satisfaction, behaviours and attitudes and, therefore, influences the organizational performance. Some authors stated that leadership styles influence employees' commitments to their job and may induce behavioural improvements that can positively impact the quality of their performance (Clark et al., 2009; Hartline et al., 2003)

In the following review of literature, we will focus on studies regarding three leadership styles: autocratic (transactional), democratic (transformational) and laissezfaire (liberal), which were first suggest by Bass (1990) and further developed by Judge and Piccolo (2004) and Erkutlu (2008).

Different styles of leadership can have different effects on the employees' overall job-satisfaction. Democratic (transformational) leaders motivate their followers beyond personal interests (Quinta et al., 2015) and can become strong role models for their employees (Bass, 2008). At the same time, autocratic (transactional) leadership styles focus on the exchange between leaders and followers (Ricard et al., 2017), while also offering clear direction and practicing strict control and evaluation of their employees (Van Wart, 2012). Laissez-faire (liberal) leaders tend to be more disconnected from the day-to-day operations of their companies, relieving themselves from operational duties and focusing on more important problems, such as strategic planning and management (Krieger, 2001; Mihai, 2015a).

The autocratic (transactional) leadership theory proposes a strong top-down approach (Ricard et al., 2017). The basis of this theory is the fact that the only right way to lead is through strict direction and control, focusing at the same time on a clear reward and punishment system for the employees. However, autocratic (transactional) leaders, while being presented as a supervisor, are still supposed to lead and provide guidance to their followers (Ricard et al., 2017). This leader relies mostly on rational incentives and processes in order to fulfil the organization's goals and clear hierarchy and high-power distance characterize his/her relationship with subordinates. They are strongly task oriented, set and monitor clear goals and objectives, exert control and strictly evaluate the performance of their employees (Van Wart, 2012).

Autocratic (transactional) leaders tend to focus on the lower levels of Maslow's hierarchy of needs. They rely on a transaction model in which employees are rewarded for their achievements and punished for their failures (Bass, 1990). They are seen as very effective in "getting specific tasks completed by managing each portion individually" (Hargis et al., 2011, p.54)

Autocratic (transactional) leadership can be defined as a leader-subordinate relationship based on a series of exchanges and understandings between leaders and subordinates (Tintore, 2019). Those who participated in these transactional exchanges at work were formed in the quid pro quo, i.e., clearly defined roles, where the manager decides, and the subordinate executes. The exchange, or understanding, usually consists of a financial reward for the hours worked, without any personal recognition of subordinates' skills or achievements (Tintore, 2019).

Bass (2008) characterized autocratic (transactional) leaders as those who 
operate in existing systems or cultures. Moreover, he stated that transactional leaders are concerned with efficiency and time management, preferring to avoid risks and use processes and techniques that have proven their functionality in experiences. These leaders feel more comfortable in easy-to-predict situations where past performance could be used to indicate future success. To test his theories, since the 1980s, Bass has conducted a series of experiments that have resulted in the emergence of two transactional factors, situational reward and exception management.

The situational reward was represented by the employees' desire to know what they need to do to receive rewards, while the exceptional management indicated the employees' desire to perform the tasks in the traditional way. Moreover, the researchers stated that the situational reward usually has a stronger correlation with the results than the management by exceptions, especially the passive one.

The democratic (transformational) leadership style is thought to be able to bring change in the organization (Ricard et al., 2017). This perspective builds on the transactional theory, which highlights the connection between leaders and followers and adds a supportive approach, which complements the directive approach of autocratic (transactional) leaders. Democratic (transformational) leaders are charismatic and they are able to change the organization from within, as well as the people in it, in order to fulfil their goals (Tintore, 2019). This means that democratic (transformational) leaders recognize the need for change and innovation and implement their vision by motivating their followers (Bass, 2008). This theory places the leader in the center of the organization (Quintana et al, 2015).

The theory of democratic (transformational) leadership is based on the research undertaken by Burns (1978) and involved both leaders and subordinates working together to increase the level of motivation related to achieving an idealistic goal. This idealistic goal was one in which the direction and aspirations of both leaders and subordinates were combined into a single vision (Askehave and Zethsen, 2014). Democratic (transformational) leaders sought to energize subordinates, individually, without restricting their range of basic needs; thus, leaders sought to meet the higher needs of subordinates. Thus, they motivated their subordinates to aspire to organizational goals. In other words, if an organization views employees as individuals, they can become more loyal to the company.

Alonso-Almeida et al., (2015) stated that democratic (transformational) leaders possess strongly motivating behaviours, provide models for defining traits, values, beliefs and behaviours that should be imitated by subordinates, are visionaries in terms of articulating an ideological goal, and inspire confidence in subordinates, while providing intellectual stimulation and support.

Tintore (2019) stated that democratic (transformational) leaders connect with the needs and expectations of subordinates, motivate them, energize their mental and emotional resources, and enthusiastically involve them in the work to be done. Transformational leaders are often also called participatory or democratic leaders (Banks et al. 2016).

Democratic (transformational) leaders contribute to organizational change through their words, actions, speeches and behaviours, having a considerable influence on subordinates. This type of leadership occurs when leaders are able to develop subordinates' interest in the work they do, the organization's goals, mission, and vision, and to encourage them to think beyond individual goals (Mihai, 2018).

Democratic (transformational) leaders encourage their subordinates to look at old issues from new perspectives, work for organizational goals, and motivate them to act beyond self-interest. These leaders are able to share their vision with their subordinates to the point where they adopt that vision as if it were their own. At the same time, transformational leaders have 
the ability to coordinate their subordinates, create coherence throughout the system, and direct the entire organization toward vision (Banks et al. 2016).

Contrary to the autocratic (transactional) leaders, which focus on the lower levels of Maslow Hierarchy of needs, democratic (transformational) leaders target the upper levels, such as the need for social relation, respect and self-realisation (Tintore, 2019).

The Laissez-faire (liberal) style derives from the democratic (participatory) leadership style, with the difference that the leader's involvement in the activities of his subordinates is minimal. This is one of the most controversial leadership styles, in the sense that some researchers even say that it implies the lack of any leadership behaviour (Mihai, 2015a). Employees have complete freedom to make decisions that govern their activities and have to solve problems on their own with very little guidance from leaders (Quintana et al, 2015).

Although this style of leadership may seem similar to passive management-byexception (an element of autocratic/transactional leadership), Bass (2008) and Avolio (1999) argue that laissezfaire leadership represents a completely different leadership style, with clear differences from the autocratic (transactional) and democratic (transformational) styles.

The Laissez-Faire style is characterized by the fact that all the prerogatives of the leader are delegated to subordinates, who give them little (if any) support. If the leader is not involved in organizational activity, this lack of involvement can lead to a decrease in labour productivity, cohesion and satisfaction among subordinates (Arbaiza and Guillen, 2016).

This style, even though it may seem like a style used by lazy, irresponsible leaders, can be used, but successfully, in a company that has reached maturity. The leader can focus on administrative or strategic decisions, letting his employees organize and complete the company's operational activities, as they are sufficiently competent and experienced, and day-to-day activities have become routine and the chances as an unexpected situation to occur are quite small. This can be advantageous for them to adhere to, which can focus on the more important and complex aspects of the company.

Despite the advantages presented above, some employees cannot work efficiently without guidance, cannot manage their own time and, if given full freedom, their actions can have a negative impact on the company's performance. Moreover, given that in most cases (and especially in the case of small or medium-sized enterprises), subordinates tend to take over certain aspects of leaders' behaviour, chances are that their non-involvement will lead to a decrease in team members' interest in the activity they have to carry out.

Mendez, Vera Munoz and Vera Munoz (2013) conducted a study that analysed the relationship between the three behavioural leadership styles presented above (autocratic/transactional,

democrat/transformational and laissezfaire/liberal) and organizational efficiency among small and medium enterprises in the field construction, in Puebla, Mexico. Its results showed that 1 ) there is a positive and significant correlation between organizational efficiency and democratic and liberal styles (laissez-faire); 2) there is a negative correlation between organizational efficiency and autocrat style.

All of the aforementioned scholars have focused their research of leadership styles on large organisations, the literature lacking relevant studies regarding leadership styles in small and medium enterprises. Unlike larger organisations, which have multiple levels of management and where the leader exerts his influence only upon his direct subordinates, a small business has a leaner organizational structure, the leader is usually also the owner and his relationship with his employees is more direct and personal (Mihai, 2015a). Many researchers agree that a small business ownermanager's leadership style can significantly affect the satisfaction of all his employees, and therefore, the overall performance of 
his company (Bass, 2008; Gordon and Yukl, 2004; Peris-Ortiz et al., 2012; Mihai, 2018); the SME's success or failure being a direct effect of the leader's attitudes and behaviours (Chaganti, Cook and Smeltz, 2002).

The present papers' authors' previous doctoral research focused on the study of leadership styles among Romanian (Mihai, 2015a) and Dutch (Mihai, 2015b; Mihai et al., 2017) small and medium enterprise owners, as well as on a comparison between the findings in each country (Mihai, 2016). The findings have shown that in both cases, the small and medium business ownermanagers mostly tend to adopt the democratic/transactional style (Mihai, 2015a; Mihai, 2015b).

The SMEs are considered to be the backbone of every national economy (Rotaru et al., 2020) and even more so the engine of the European Union's economic development (Mihai, 2018), since they represent $99.8 \%$ of the European Union's 20 million enterprises (Moritz, 2011). Small and medium businesses contribute to an average of $50 \%$ of the Gross Domestic Product of developed countries (Mihai, 2015 b), while employing roughly $75 \%$ of the total workforce in OECD countries (Mihai 2015b).

In Spain, according to Eurostat Data for 2018 (SBA Fact Sheet for Spain, 2019, p.2), there were around 2.79 million enterprises, out of which 2.78 (99.9\%) are small and medium enterprises (less than 250 employees, an annual turnover of less than $€ 50$ million and total assets of less than $€ 43$ million). According to SBA Fact Sheet for Spain (2019, p.1), "small and medium-sized enterprises (SMEs) generate $61.3 \%$ of total value added and $71.9 \%$ of total employment in Spain. Between 2014 and 2018, SME value added rose by $19 \%$ and employment by $13.5 \%$. The outlook for SMEs in Spain continues to be positive. SME value added is expected to grow again by $6.4 \%$ between 2018 and 2020. Over the same period, SME employment is forecast to increase by $2.8 \%$, with an expected 249,600 new SME jobs created by $2020 . "$
Regarding Catalonia, according to CEIC Data, in 2017 there were over 618.000 private enterprises (https://www.ceicdata.com/en/spain/nu mber-of-companies-by-region/no-ofcompanies-catalonia), out of which more than $519.000 \quad(83 \%)$ were SMEs, representing $59.6 \%$ of the total value of Catalan GDP (Catalan News, 2017.

We cannot discuss the small business environment without taking into account the impact of the COVID-19 pandemic, which has affected business from all across the world. In order to protect the population and slow the expanse of the pandemic, on the 13th of March 2020, the Catalan government adopted several measures which greatly affected the business environment, among which we should mention the closing of restaurants, bars and cafes (except those offering delivery and takeaway services), retail stores and shopping centers (except those exclusively dedicated to essential goods), theatres, cinemas, nightclubs, discotheques, pubs, dance halls, concert halls, and any other recreational establishment, as well as gambling establishments and amusement parks, theme parks and any another centre devoted to entertainment or leisure activities, including sporting facilities and sports clubs (El Nacional, 2020). These measures were in place until the end of May 2020. In October 2020, when new cases of COVID-19 infections reached new records, the Catalan government reinstated some of these measures, closing again restaurants, bars and cafes (except those who offer takeaway and delivery services), while limiting the customer capacity of physical retail units to $30 \%$ of the normal capacity (except for stores which offer essential goods and medicine, which were allowed to function with $50 \%$ of the normal customer capacity) (Barcelona.cat, 2020)

As of 16th of April 2020, more than 90,000 companies (most of them SMEs) asked for temporary layoffs requests (ERTOs), affecting over 660.000 workers who remained temporarily unemployed, their work contract being suspended (Catalan News, 2020) 
It is important to mention, that besides regulations which restricted the operation of business, the Catalan government also implemented a series of measures meant to aid those businesses affected by the pandemic. According to a Catalan government document called "Aid for productive activity and employment due to the effects of coronavirus" (Generalitat de Catalunya, 2020), these measures included but were not limited to the following:

- An Emergency Employment Plan with a value of $€ 59.29$ million which benefits 1,500 companies and 4,300 workers (Generalitat de Catalunya, 2020);

- $\quad € 70$ million to finance the liquidity needs of Catalan SMEs (Generalitat de Catalunya, 2020);

- $€ 1$ billion credit line of loans for the self-employed and the businesses affected by the pandemic, $100 \%$ guaranteed by the Catalan government (Generalitat de Catalunya, 2020);

- An extension of tax deadlines until the end of the state of alarm decreed by the Spanish government (Generalitat de Catalunya, 2020);

- Creation of "Business Marketplace COVID-19", an online service dedicated to connecting the offer and the demand of goods and services dedicated to face the COVID-19 pandemic (Generalitat de Catalunya, 2020).

\section{Research Methodology}

This article aims to analyse the leadership styles of SME owner-managers from Catalonia, Spain and to understand how these leadership styles are influenced by different variables. The article analyses how the COVID-19 pandemic affects the Catalan small business environment and what are the respondents' perceptions regarding the Catalan government measures that were meant to support the business environment.

In order to fulfil our research objectives, we have conducted a quantitative research study using an online questionnaire with 24 questions, which was applied to small and medium business owner-managers from Catalonia, Spain. In order to gather the relevant data, we have distributed our survey to over 450 Catalan entrepreneurs, from which we gathered almost 200 responses, 164 of them being validated as relevant for this research. We have invalidated more than 30 responses for being incomplete (the respondent did not answer all the questions) or for failing several statistical reliability tests. In 5 invalidated cases, the responses were complete as well as statistically reliable, but the respondents were not the ownermanager of the company or their company did not fit in the SME category.

The entrepreneurs, which had been given the survey, were selected in an arbitrary way, mainly with the support of different professional organisations, which represent the SME environment from Catalonia, several NGOs, Facebook groups and discussion forums, as well as through the personal connections of the authors. It's important to mention that this study is based on empirical research, since the authors could not travel to Catalonia due to the COVID-19 pandemic and at the same time, had limited time and resources which were not sufficient for conducting more complex scientific research.

Our questionnaire was divided into three parts, the first part regarding general information about the respondent and his business, the second related to the identification of the respondents' leadership style and the last part regarding the impact of the COVID-19 pandemic. The first part included questions related to sex, age and education level of the respondents, as well as regarding his position in the company (only responses from the ownermanagers of SMEs were included in this study), the SME category (micro, small or medium), the industry in which his business activates, as well as the age of the company. The second part of the survey comprised 15 questions which measured (using a 5-point Likert scale, ranging from total disagreement to total agreement) respondents' attitude regarding their employees, how they make decisions and 
assign tasks, how they evaluate their subordinates and what degree of autonomy and responsibility are they giving them. These 15 questions were divided into 3 sets of 5 questions, each set being related to one of the three leadership styles (autocratic/transactional,

democratic/transformational/ and laissezfaire/liberal). The 3 sets of questions were randomly spread across the survey, so the respondents wouldn't find the pattern and be as objective and honest as possible in their answers. The questions regarding the leadership style were adapted from two online surveys (Sagepub and NWlink). In order to identify the dominant leadership style of each respondent, we have added the score from each question in every set and considered the style with highest score as being dominant. The dominant style of each participant was used in the analysis and the discussion of the results.

The last part of the survey included two questions, one related to the operational capacity reduction of the respondents' business due to the COVID-19 pandemic and the other which included 8 Likert-scale statements, related to the impact of the COVID-19 pandemic and the respondents' perception regarding different aid measures implemented by the Catalan government.

It's important to note that this research is a continuation of the authors' previous doctoral research which studied the leadership styles of SME owner-managers from Romania and the Netherlands, as well as the correlation between these styles and several variables and thus, we have tried to keep the survey similar to the ones used in Romania and the Netherlands in order to be able to continue this research with a comparison between the three countries.

The results of this study were processed through MS Excel and IBM SPSS Statistics and the results are discussed below.

\section{Results and Discussion}

\section{Sample Distribution}

Our sample is represented by 164 ownermanagers of small and medium enterprises from Catalonia, Spain where 51\% (84 respondents) were female and 49\% (80 respondents) were male. Considering that as of 2010 , only $36.4 \%$ of Catalan businesses were owned by female entrepreneurs (Noguera, 2012), the large proportion of female respondents in our survey may imply a lower degree of the sample's representativeness (Badea, 2017).

From the 164 SMEs included in this research, 133 (81\%) were microenterprises, 25 (15\%) were small enterprises and $6(4 \%)$ fit in the medium enterprise category.

Out of the 164 respondents, $45 \%$ (73 respondents) were managing businesses in the hospitality industry, $27 \% \quad(45$ respondents) were running a business in the service industry, 15\% (25 respondents) were involved in retail activities, while 13\% (21 respondents) were involved in the manufacturing business. Thus, we have a distribution of $27 \%$ of the respondents' running businesses in the secondary sector and $73 \%$ of the respondents' running business in the tertiary sector. Considering that Catalonia's main contributor to the regional gross value added (GVA) is the tertiary sector (EU's Regional Innovation Monitor Plus, 2017), which accounted for $71.5 \%$ of the total in 2017 , we can state that our sample is representative for the Catalan business environment, since the distribution of our sample is very similar to the regional distribution.

Moreover, another descriptive statistics variable that we found important for the aim of this study is the maturity of the respondents' businesses. Thus, $16 \%$ of the total sample population have been running their business for less than 3 years, $27 \%$ have a business for more than 3 years but less than 5 years, 33\% have been running their business for more than 5 years but less than 10 years, while $24 \%$ have had a business for more than years.

Badea (2017) arrived at the conclusion that the female entrepreneurs of Catalonia are more receptive to participating in these 
kinds of studies, thus showing that they are able to understand the importance of scientific studies on the business environment are more concerned with ethics and development.

In order to answer the first research question, we have studied the distribution of the leadership styles of the sample population. The leadership styles have been identified according to the entrepreneurs' responses to the three sets of questions, as it was explained in the "Research methodology" part of this paper. Thus, as we can see from Fig. 1, 43\% (71 respondents) of our respondents were identified as democratic/transformational leaders, 34\% (55 respondents) of the entrepreneurs were identified as laissez-faire (liberal) leaders, while $23 \%$ (38 entrepreneurs) of the respondents were identified as autocratic/transactional leaders. Thus, most of our respondents were identified as democratic/transformational leaders, but the differences are not significant enough in order to safely say that the Catalan SME environment is dominated by one type of leadership or the other.

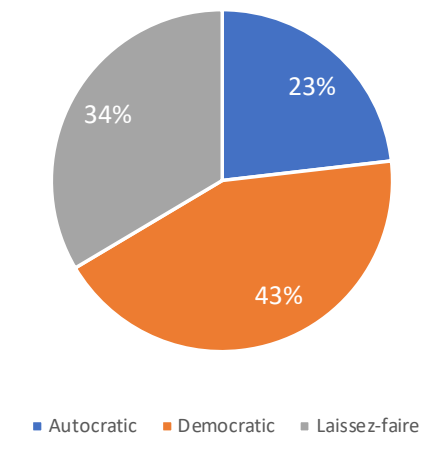

Fig 1. The leadership styles of SME owner-managers from Catalonia, Spain Source: authors' processing

In order to fully understand the causes of this result, we discuss several aspects, which may have influenced the distribution of leadership styles among our sample. First of all, we need to discuss Hofstede's cultural dimensions, which are an important determinant for the attitudes and behaviours of individuals which form a certain culture.

Nowadays, Hofstede's website (www.hofstede-insights.com/spain) measures 6 cultural dimensions (as opposed to the original 4). Thus, we have (a) Power Distance, (b) Individualism, (c) Masculinity, (d) Uncertainty Avoidance, (e) Long Term Orientation and (f) Indulgence. We will discuss each of them in particular, their values for the Spanish culture (as we did not find any relevant data regarding Catalonia in particular), as seen in Table 1, and their implication on the distribution of leadership styles in our sample. 
Table 1: Hofstede's Cultural Dimensions for Spain

\begin{tabular}{|l|l|}
\hline $\begin{array}{l}\text { Hofstede' Cultural } \\
\text { Dimension }\end{array}$ & $\begin{array}{l}\text { Score for } \\
\text { Spain }\end{array}$ \\
\hline Power Distance & 57 \\
\hline Individualism & 51 \\
\hline Masculinity & 42 \\
\hline Uncertainity Avoidance & 86 \\
\hline Long Term Orientation & 48 \\
\hline Indulgence & 44 \\
\hline
\end{tabular}

source: adapted from https://www.hofstede-insights.com/country-comparison/spain/

\section{a) Power Distance}

According to Hofstede's website, "this dimension deals with the fact that all individuals in societies are not equal - it expresses the attitude of the culture towards these inequalities amongst us. Power Distance is defined as the extent to which the less powerful members of institutions and organisations within a country expect and accept that power is distributed unequally" (Hofstede Insights, 2020). The same website sets Spain's power distance index at 57, a high score that indicates Spain is a hierarchical society, in which "people accept a hierarchical order in which everybody has a place, and which needs no further justification. Hierarchy in an organisation is seen as reflecting inherent inequalities, centralisation is popular, subordinates expect to be told what to do and the ideal boss is a benevolent autocrat" (Hofstede Insights, 2020).

In our study, only $23 \%$ of the respondents have been identified as autocratic/transactional leaders, which, at a first glance, comes in contradiction with Spain's relatively high-power distance index. In our opinion, Spain's power distance index of 57, while being relatively high, is significantly lower than many other European countries (especially, EasternEuropean, former communist countries such as Romania, Serbia, Bulgaria or Ukraine), in which autocratic/transactional forms of leadership dominate, and thus some of the "benevolent autocrat" leaders of Spain may have been identified in our study as democratic/transformational. Moreover, we need to take into account the fact that we have identified the leadership styles of our respondents based on their own answers to a set of questions, and thus, subjectivism and the respondents' desire to be seen in a certain way might have influenced the final results.

\section{b) Individualism}

"The fundamental issue addressed by this dimension is the degree of interdependence a society maintains among its members. It has to do with whether people's self-image is defined in terms of "I" or "We". In Individualist societies people are supposed to look after themselves and their direct family only. In Collectivist societies, people belong to 'in groups' that take care of them in exchange for loyalty (Hofstede Insights, 2020). Spain has a score of 51 on the Individualism index, which is considered collectivist when compared to most other European countries.

This inclination for collectivism might be an explanation for the predominance of nonautocratic (democratic/transformational 
and liberal) in our sample. This collectivist culture translates in tightly knitted teams forming at the workplace, people emphasizing teamwork and employees tending to put effort into their work without the need of strong motivational incentives from their management, thus inciting a more democratic/transformational or liberal style of management from their superiors (Burlea-Schiopoiu, 2009).

\section{c) Masculinity}

Hofstede's website states that "A high score (Masculine) on this dimension indicates that the society will be driven by competition, achievement and success, with success being defined by the winner/best in field - a value system that starts in school and continues throughout organizational life.

A low score (Feminine) on the dimension means that the dominant values in society are caring for others and quality of life. A Feminine society is one where quality of life is the sign of success and standing out from the crowd is not admirable. The fundamental issue here is what motivates people, wanting to be the best (Masculine) or liking what you do (Feminine)" (Hofstede Insights, 2020)

As we can see from Fig. 2, this dimension has a score of 42 , which is a low score that indicates a feminine society, in which most things are settled by consensus. Polarization and excessive competition are not seen very well in the Spanish society, where "children are educated in search of harmony, refusing to take sides or standing out" (Hofstede Insights, 2020). Regarding the business environment, Spanish managers are likely to involve their employees in the decision-making process, to listen to their opinions and care for their needs and expectations, in other words, having a clear democratic/transformational approach to managing their teams.

\section{d) Uncertainty avoidance}

"The dimension Uncertainty Avoidance has to do with the way that a society deals with the fact that the future can never be known: should we try to control the future or just let it happen? This ambiguity brings with it anxiety and different cultures have learnt to deal with this anxiety in different ways. The extent to which the members of a culture feel threatened by ambiguous or unknown situations and have created beliefs and institutions that try to avoid these is reflected in the score on Uncertainty Avoidance" (Hofstede Insights, 2020). A high score means a low tolerance for risk and unknown situations, while a low score implies that individuals are more likely to assume risks and have a higher tolerance for the unknown.

Of all six dimensions, uncertainty avoidance is the one that clearly defines Spain, having an extremely high score of 86 , which means that Spanish people do not like taking risks, are afraid of the unknown and are resistant to change. "For example, in a very recent survey $75 \%$ of Spanish young people wanted to work in civil service (i.e., a job for life, no concerns about the future) whereas in the USA only $17 \%$ of young people would like it" (Hofstede Insights, 2020). Related to business, this high score implies that managers do not like taking risks and letting things to chance, which denotes a more autocratic/transactional approach to leadership and management, in which the manager sets a clear direction for his company, which is expected to be followed by the employees.

\section{e) Long term orientation}

According to Hofstede's website, "this dimension describes how every society has to maintain some links with its own past while dealing with the challenges of the present and future, and societies prioritise these two existential goals differently. Normative societies, which score low on this dimension, for example, prefer to maintain time-honoured traditions and norms while viewing societal change with suspicion. Those with a culture which scores high, on the other hand, take a more pragmatic approach: they encourage thrift and efforts in modern education as a way to prepare for the future" (Hofstede Insights, 2020) 
In fig. 2, we can see that Spain has an intermediate score of 48 , which means it is a somewhat normative country. "Spanish people like to live in the moment, without a great concern about the future" (Hofstede Insights, 2020). In business, this means that the managers are rather short-term orientated, more focused on results than on people, both of which are characteristics of the autocratic/transactional leadership style

\section{f) Indulgence}

One challenge that confronts humanity, now and in the past, is the degree to which small children are socialized. Without socialization, we do not become "human". This dimension is defined as the extent to which people try to control their desires and impulses, based on the way they were raised. Relatively weak control is called "Indulgence" and relatively strong control is called "Restraint". Therefore, cultures can be described as Indulgent, if they have a high score, or Restrained, if they score low on this dimension.

As we can see from Figure 2, Spain has a score of 44, which means it is a Restrained, rather than Indulgent society, with a tendency for pessimism and cynicism. Spanish people do not put much emphasis on their leisure time and tend to control their impulses and desires, because they have the perception that their actions should be restricted by social norms. A society with these characteristics is a breeding ground for autocratic/transactional leadership styles, where the manager is not concerned with the needs and desires of his employees, looking only to maximize their productivity at the workplace, in order to meet the organizational goals.

In conclusion, we can see that the higher percentage of democratic/transformational leaders in our sample (43\%) can be explained by only two of the six cultural dimensions (Collectivism and Femininity). The other four imply, in a stronger or weaker measure, that the Spanish business environment should be characterized by autocratic/transactional leaders, which is contradicted by the low percentage of autocratic/transactional leaders in our sample (23\%). One of the explanations for this contradiction of our results and the general cultural climate of Spain might be the fact that Catalonia is the second most developed region of the country, with a GDP of 236.739 million euro $€$ in 2019 (PIB de las Comunidades Autónomas, 2020), just $0,01 \%$ lower than that of Madrid, and thus, their business behaviour may be somewhat different than the Spanish average age. Moreover, Catalonia is a multicultural society, with over 6400 foreign companies according to Invest in Spain, and it has been recently awarded the Southern European region for foreign investment (2018-2019) by the Group Financial Times (European Cities and Regions of the Future 2018-2019) and, thus, many different cultures are leaving their mark upon the Catalan business environment and the managers' practices might not only be in line with the average Spanish cultural identity.

Our results have shown that, while indeed having a larger proportion of democratic/transformational leaders (43\%), the autocratic/transactional and laissez-faire leadership styles are also somewhat well represented in our sample (23\% and $34 \%$, respectively) and, thus, while the first research question is answered, we cannot say for certain that the Catalan SMEs owner-managers are in a significant proportion democratic/transformational. A more accurate statement would be that while Catalan SME owner-managers have a slight tendency for a democratic/transformational leadership style, the Catalan business environment is well represented by all three leadership styles, a result strongly supported by the cultural evidence and arguments discussed above.

Regarding the second research question, in order to understand how the company's maturity is influencing the leadership style of the owner-manager, we used the Strategic Management Maturity Model (SMMM), developed by the Strategy Management Group (Averson et al, 2010). This model is tool aimed at managers who 
need to asses where their organization stands in terms of strategic management, to monitor progress in improving maturity of strategic management, and to allow benchmarking across organizations, or departments within one organization, in order to identify best practices. (Strategy Management Group, 2020). The model proposes eight dimensions of strategy (Leadership, Culture and Values, Strategic thinking and planning, Alignment, and Performance measurement, Performance Management, Process Improvement and Sustainability of Strategic Management) which are analysed across five levels of organizational maturity:

\section{a) Level 1: Ad Hoc and Static}

It is characteristic of organizations at this level that they currently do not do any strategic planning or management in a formal sense, tending to plan only on the tactical or operational level in an ad hoc and uncontrolled manner, normally by senior management behind closed doors. Leaders spend a majority of their time addressing operational issues and "putting out fires" and never address long-term strategy (Strategy Management Group, 2020).

\section{b) Level 2: Reactive}

It is characteristic of organizations at this level that some elements of effective planning and strategic performance management are being applied, only in an inconsistent fashion and often with poor results. Planning discipline is unlikely to be rigorous, and only happens in reaction to events or to temporarily please an individual leader. These organizations might measure performance or even use it to punish underperformers, but often these activities are done by individuals to meet a routine policy need and are not taken seriously. (Strategy Management Group, 2020).

\section{c) Level 3: Structured \& Proactive}

It is characteristic of organizations at this level that there are formal structures and processes in place to comprehensively and proactively engage in strategic planning and management. These activities occur on a regular basis and are subject to some degree of improvement over time. Measurements are somewhat aligned with strategy and employee accountability is taken seriously. (Strategy Management Group, 2020).

\section{d) Level 4: Management \& Focused}

It is characteristic of organizations at this level that strategy drives focus and decision making for the organization. Organizationwide standards and methods are broadly implemented for strategy management. Leaders formally engage employees in the process and a measurement \& accountability work culture help drive strategic success for the organization (https://strategymanage.com/resources/s trategic-planning-basics/strategicmanagement-maturity-model/).

\section{e) Level 5: Continuous Improvement}

The strategic planning and management excellence are embedded within the culture of the organization and are continuously improved in a formal sense, that it is a characteristic of organizations at this level. This means that as performance is evaluated, the organization first analyses how it is performing towards its strategic goals and then second studies how effective the strategic planning and management processes are and adapts as necessary. Excellence in strategic management drives the organization's competitive edge or performance success. (Strategy Management Group, 2020).

The main drawback of this model is the fact that the five maturity levels are not directly linked to the age of the company, which represents the main variable with which we measure the maturity in our study. For the purpose of this study, we assumed that the first two Levels are applied to companies less than 3 years old, Level 3 is applied to companies between 3 and 5 years old, Level 4 is applied to companies between 5 and 10 years old and Level 5 is applied to companies older than 10 years. 
Regarding the leadership dimension, the model proposes the following approach:

Level 1 - Leaders dictate/command \& control; otherwise disengaged

Level 2 - Leaders dictate but gather feedback sporadically

Level 3 - Leaders engage with direct reports only, but do model desired behaviours and values

Level 4 - Leaders empower many employees through ongoing engagement

Level 5 - Leaders \& employees fully engage in a continuous dialog based on a team-

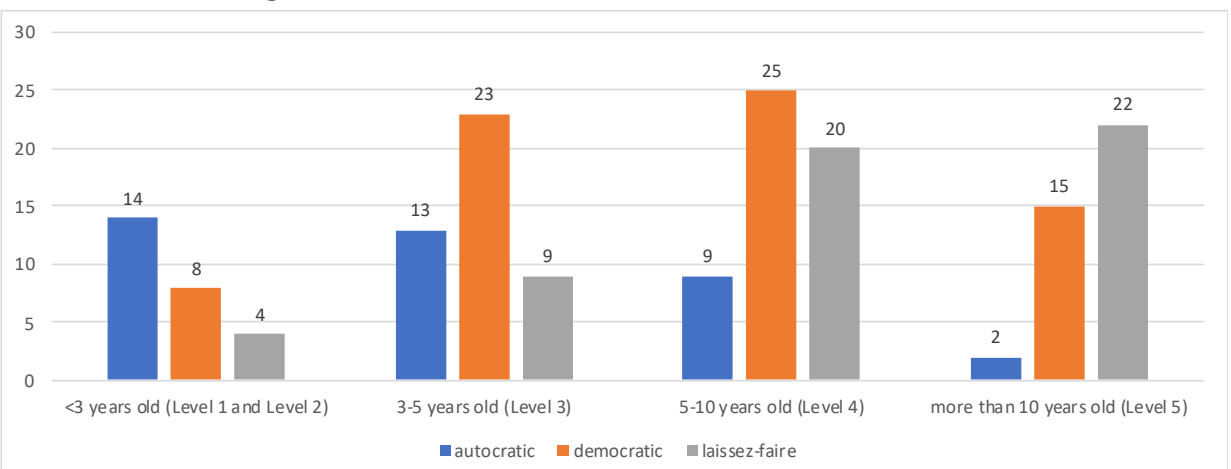

Fig. 3: The correlation between the company's maturity and the owner-manager's leadership style

Source: authors' processing

As we can observe from Figure 3 , the distribution of leadership styles varies significantly among different maturity levels. Thus, in companies less than 3 years old (Level 1 and Level 2 from SMMM), most of the leaders from our sample were autocrats (53\%). The percentage of autocratic/transactional leaders lowers constantly as we look at the other three maturity levels: $29 \%$ in $3-5$ years old companies (Level 3), $17 \%$ in $5-10$ years old companies (Level 4) and 7\% in companies older than 10 years (Level 5). The percentage of democratic/transformational leaders is more or less the same in the last three maturity levels (even though the actual number of leaders increases in the first three levels and decreases in the last), while the first being significantly lower: $30 \%$ in the first maturity level, $51 \%$ in the second maturity level, $46 \%$ in the third maturity level and $51 \%$ in the last. As for laissez-faire leaders, their presence is scarce in the first two levels $15 \%$ in the first based culture (Salamzadeh \& Hajiseydjavadi, 2016, p.89)

We have decided to look into the correlation between the company's maturity and the owner-managers leadership style in order to understand if the age of the company plays any role in the distribution of leadership styles among our sample. The findings shown in Fig. 3 are discussed below. and $17 \%$ in the second), but their proportion increases significantly if we look at older companies (37\% for companies aged 5-10 years old and 75\% in companies older than 10 years).

Thus, our findings show a tendency of the SME owner-managers to lower their authority as the company ages: they tend to be more autocratic/transactional in the young companies, democratic/transformational in companies, which are in the growth and development stage, and liberal in mature companies. The reason for this might be the fact that in a young company (less than 3 years old), the employees are often inexperienced and need guidance and direction from their leader, who doesn't have yet full confidence in them and their abilities to fulfil their tasks and objectives, and at the same time, a young company encounters many obstacles in its day to day operations (this being the stage in which many companies fail and end 
up closing their operations) and, thus, the leader needs to be actively involved in solving the problems which may arise at an operational level and to have an active role in steering the company on the right path in crisis situations.

As the company matures and reaches the growth and development stage (3-10 years old), employees become more experienced, more capable to solve on their own whatever problems might appear in the company's day to day operations, and the leader's confidence in them and their abilities grows. It's important to note that at this stage, some SME owner-managers might employ a middle-lever manager to run the company's day to day operations, and his or her involvement in the operational side of the company starts to diminish so he or she can focus on the more important issues, such as strategic planning and management.

A mature company, which has been on the market for more than 10 years, has very experienced employees and multiple levels of middle management and thus does not need the direct involvement of the ownermanager in its day-to-day operations, a fact that explains the prevalence of laissez-fair leaders in Level 5 companies. An important thing to mention is the fact that laissez faire leaders are also prevalent in some SMEs aged between 5 and 10 years old, the reason for this being that different companies mature at different speeds and it is entirely possible for some companies to have reached the last level of maturity earlier than 10 years.

In order to further study the correlation between the company's maturity and the owner's leadership style, we have analysed the Pearson correlation between two variables: (1) the company's maturity and (2) the leaders' degree of involvement in the company's day to day operations (considering autocratic/transactional leaders have the highest degree of involvement, followed by democratic/transformational leaders and laissez-faire leaders, which have the lowest degree of involvement in the day to day operations). The results are shown in Table 2.

Table 2 : Pearson correlation between company's maturity and leader's involvement

\begin{tabular}{|l|l|l|l|}
\hline \multicolumn{2}{|c|}{} & Leader's Involvement & $\begin{array}{l}\text { Company's } \\
\text { maturity }\end{array}$ \\
\hline \multirow{2}{*}{$\begin{array}{l}\text { Leader's } \\
\text { Involvement }\end{array}$} & $\begin{array}{l}\text { Pearson } \\
\text { correlation }\end{array}$ & 1 & $-.229^{*}$ \\
\cline { 2 - 4 } & Sig (2.dim) & & .001 \\
\hline $\begin{array}{l}\text { Company's } \\
\text { maturity }\end{array}$ & $\begin{array}{l}\text { Pearson } \\
\text { correlation }\end{array}$ & $-.229^{*}$ & 1 \\
\cline { 2 - 5 } & Sig (2.dim) & .001 & \\
\hline
\end{tabular}

Source: authors' processing

Our findings show a Pearson Correlation of $-0,229$ between the leader's involvement in the day to day operations and the company's maturity, with a sig. value of .001 , which supports our previous findings that the company's maturity is influencing in a direct and negative way the leader's involvement in the day to day operations.
We continue our study of the Catalan SME's owner-managers' leadership styles with an analysis of the correlation between the respondents' gender and their leadership style. Our findings are shown in Fig. 4. 


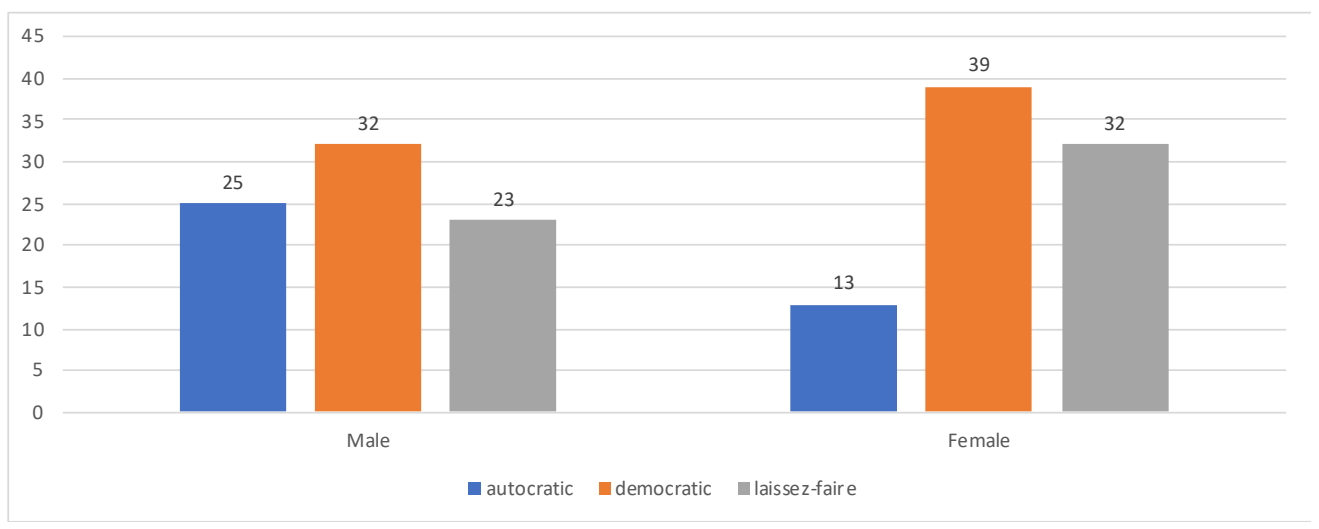

Fig. 4: The distribution of leadership styles across genders

Source: authors' processing

Looking at Fig. 4, we can see that in case of both genders, the dominant leadership style is democratic/transformational, which was to be expected, considering the leadership style's prevalence in our sample $(43 \%)$ of total respondents. However, it is important to note the distribution of the leadership styles across the two genders. Thus, in the case of male respondents, the three styles are somewhat evenly distributed: $40 \%$ identified as democratic/transformational leaders, $\quad 31 \%$ identified as autocratic/transactional leaders while 29\% identified as laissez-faire leaders. In the case of female respondents, the three styles are not so evenly distributed: $46 \%$ are democratic/transformational leaders, 39\% are laissez-faire leaders and only $15 \%$ are autocratic/transactional leaders. Thus, even though both genders favour the democratic/transformational style, the main difference appears regarding the autocratic/transactional style: the proportion of male autocrat leaders is significantly higher than the proportion of female autocratic/transactional leaders.

Our results are in line with other authors' findings. Garcia-Solarte, Garcia-Perez-deLema and Madrid-Guijarro (2018, p.529) have studied this issue in a Colombian context and their results have shown that "companies with greater gender diversity (mostly women on the board of directors and in management) develop a transformational (democratic/transformational) organizational style orientated towards organizational change through the transformation of followers", rather than a transactional (autocratic/transactional) style focused on constant control and direction, as well as based on material rewards. Moreover, Eagly and Carli (2007), distinguished researchers on gender differences in leadership styles, found that the differences between male and female leadership styles are small, but they do exist. Levy (2010) found that these small differences are statistically significant regarding how males and females practice their leadership style, as well as how they are perceived in management positions and their efficiency in these positions. Other authors, such as Andersen and Hansson (2011, p.435) found that "women adopted participative styles of leadership and were more transformational leaders than men who adopted more directive and transactional styles of leadership".

Female leaders have a tendency to employ communal behaviours, such as affiliation, nurturing, communication and cooperation, while male leaders tend to display agentic behaviours and are more goal and task oriented, independent and focused in their decision-making process (Levy, 2010; Andersen \& Hansson, 2011). Gordon and Yukl (2004) and Trinidad and Normure (2005) also studied this issue and came to the conclusion that female leaders are more likely to be inclusive, sensitive and nurturing and found that women scored higher than men on several skills such as teamwork, stability, motivation, 
recognizing trends and acting on new ideas. Forsyth (2010, p.113) stated that "women tend connect more with their group members by exhibiting behaviours such as smiling more, maintaining eye, and are more diplomatic with their comments". Another important study on this matter was conducted by the Management Research Group (2013, p.23) which found that "out of common leadership competency areas surveyed, women were rated higher by their superiors in areas like credibility with management, future potential, insight, sensitivity, and working with diverse people. Men were ranked higher in business aptitude, financial understanding, and strategic planning, which the researchers note are seen to be critical to corporate advancement. No gender differences were found in competencies such as team performance, effective thinking, and willingness to listen and no differences were found in overall effectiveness". It's important to note that several studies regarding the employees' perception of their superiors have found that females leaders are perceived as less dominant than their male counterparts and that they "lose authority... if they employ feminine styles of leadership in male dominated roles" (Levy, 2010, p.372).

Most of these studies have the same limitation as ours, the fact that the results are based on the respondents' self-report data, which are considered somewhat unreliable by some researchers (HamoriOta, 2007). These differences in leadership behaviours may not be generalizable across all teams and situations and it is very difficult to predict a person's behaviour in a leadership position.

We must note that there are several studies, which did not find any significant differences in the leadership behaviour of male and female leaders. Andersen \& Hansson (2011) conducted a study on public managers regarding their leadership and decision-making styles as well as motivation profiles and found some differences only regarding decision-making, but none was considered significant. Kent \&
Schuele (2010) analysed a large sample of German male and female leaders and found no difference regarding transformational (democratic/transformational) leadership behaviours. Cliff (2005) studied male and female SME owner-managers (as opposed to many of the aforementioned studies which analysed managers from different levels) and found no significant difference in their leadership behaviour. Another similar study was conducted by Dobbins and Platz (1986) which found that male and female leaders exhibit equal amounts of task oriented and people-oriented behaviours and their subordinates are equally satisfied.

This being said, we can conclude that while male leaders may be somewhat more inclined to exhibit autocratic/transactional leadership behaviours, there are not any significant differences between the leadership styles of male and female SME owner-managers.

In order to analyse how the COVID-19 pandemic has affected the small and medium enterprises from Catalonia, first we asked our respondents how the crisis affected their business from an operational point of view. Thus, 10 of the respondents' companies (6\%) are fully operational (100\% of normal capacity), 31 respondents $(19 \%)$ are running at a capacity between $75 \%$ and $100 \%$ of normal capacity, 43 respondents (26\%) are operational between $50 \%$ and $75 \%$ of normal capacity, 52 respondents (31\%) have reduced their operations to more than $50 \%$ and 28 respondents $(18 \%)$ stated that their business was not operational when this study was conducted. Thus, we can see that $94 \%$ of our respondents were more or less affected from an operational point of view by the current crisis. In consensus with Burlea-Schiopoiu et al. (2017).

We continue our analyses with the correlation between operational capacity reduction and the company's industry in order to understand which were the industries most affected by the pandemic. The results are shown in fig. 5 


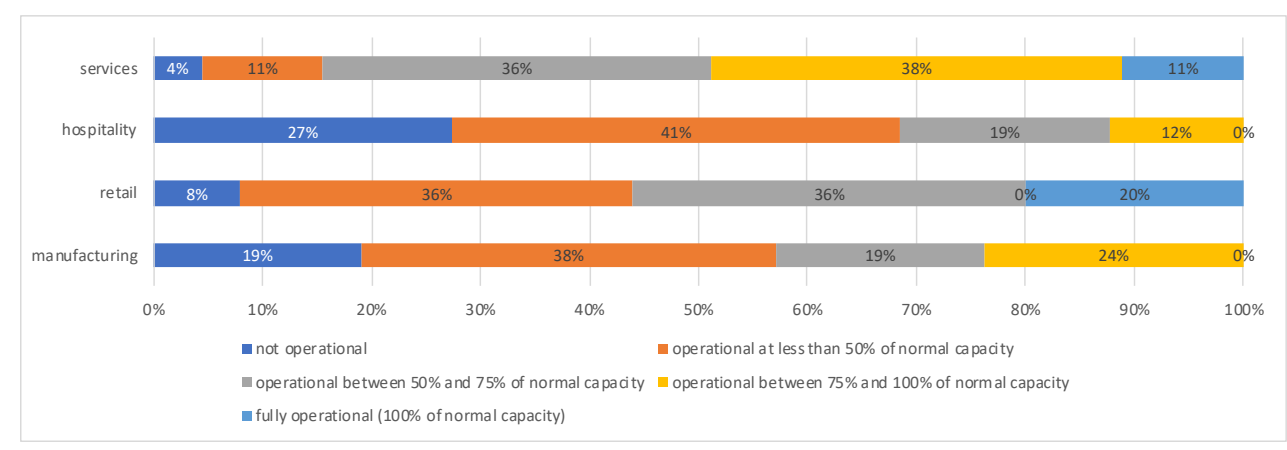

Fig 5. The correlation between operational capacity reduction and industry Source: authors processing

Our findings are showing us that $4 \%$ of the services companies included in our sample are not operational, $11 \%$ are operational at less than $50 \%$ of the normal capacity, $36 \%$ are operational between $50 \%$ and $75 \%$ of normal capacity, $38 \%$ are operational at more than $75 \%$ of normal capacity and $11 \%$ are fully operational. We can observe that the hospitality industry has been the most affected in our sample: $27 \%$ of the companies are not operational at the moment of the study, $41 \%$ are operational at less than $50 \%$ of normal capacity, $19 \%$ are operational between $50 \%$ and $75 \%$, $12 \%$ are operational at more than $75 \%$ and not one company from this industry which was included in our sample is fully operational. Regarding the retail industry, $8 \%$ of the companies included in our sample are not operational, $36 \%$ are operational at less than $50 \%$ of normal capacity, $36 \%$ are operational between $50 \%$ and $75 \%$ of normal capacity, not a single company is operational at more than $75 \%$ of normal capacity and $20 \%$ are fully operational. In the manufacturing industry, we can observe that $19 \%$ of our respondents' companies are not operational, 38\% are operational at less than $50 \%$ of normal capacity, $19 \%$ are operational between $50 \%$ and $75 \%$ of normal capacity and $24 \%$ are operational at more than $75 \%$ of normal capacity, but not a single manufacturing company included in our sample is fully operational.

As we can see, the hospitality companies from our sample have been the most affected by the COVID-19 pandemic. This was to be expected, considering that the
Catalan government restrictions have mostly targeted restaurants, bars, cafes and to a lesser extend hotels and other accommodation units: during the initial phase of the new Coronavirus pandemic, bars and restaurants were closed (except those offering delivery and takeaway services), a measure that was reimposed on the 16 th of October, when the daily number of people diagnosed with COVID-19 reached new records (Barcelona.cat, 2020). A significant part of the hospitality industry was forced to fully close: indoor bars and clubs, as well as restaurants which do not offer takeaway or delivery services, which might explain why $27 \%$ of the hospitality companies included in our study were closed at the moment the study was conducted. This finding is further supported by Barcelona's restauranteurs association claim that until the end of the year, $38 \%$ of the city's bars and restaurants will be out of the business (TheLocal.es, 2020). A main cause for this being the region's, and even more so Barcelona's, dependency on tourism, which has sharply declined since the start of the pandemic.

These measures also affected (albeit in a lesser measure) the retail industry: stores and stops were forced to limit their customer capacity to $30 \%$ of the total capacity, with the exception of retail units selling basic necessities (food, groceries, medicine) which could function with their customer capacity limited to $50 \%$ of the normal capacity (Barcelona.cat, 2020)). These regulations support our finding that $44 \%$ of our respondents who own and 
manage a retail company either are closed or function at less than $50 \%$ of normal capacity. An interesting result is the fact that $20 \%$ of the retail companies included in our samples stated that they are functional, which means they only operate online shops and stores, with no physical location and, thus, were not affected, in any measure, by the government regulation.

Our findings have shown us, that among our respondents, those who own and manage business in the services sector (transport, distribution, IT, marketing, home delivery, telecommunications, professional services, etc.) were the least affected by the COVID-
19 pandemic, a result that can be explained by the fact that the government restrictions did not target them directly. Moreover, certain types of services such as home delivery flourished during the pandemic.

Furthermore, we continue our study with the analysis of the respondents' perception regarding the COVID-19 pandemic. We have asked our participants to rate 8 statements with a 5-point Likert-scale, ranging from 1 Extremely Disagree to 5 - Extremely disagree. The questions as well as the mean value of the respondents' ratings are presented in Table 3.

Table 3 - Respondents' perception of how the COVID-19 pandemic affected their business

\begin{tabular}{|l|l|l|l|}
\hline & Question & Mean & $\begin{array}{l}\text { Standard } \\
\text { Deviation }\end{array}$ \\
\hline 1 & $\begin{array}{l}\text { In my opinion, the government restrictions are too harsh for the } \\
\text { business environment }\end{array}$ & 2.42 & .512 \\
\hline 2 & $\begin{array}{l}\text { The demand for my products/services has been significantly } \\
\text { reduced during this crisis }\end{array}$ & 4.12 & .576 \\
\hline 3 & $\begin{array}{l}\text { I had to increase the price of my products/services in order to } \\
\text { compensate the lack of demand }\end{array}$ & 3.11 & .663 \\
\hline 4 & I had to temporarily layoff a significant part of my workforce & 3.49 & .457 \\
\hline 5 & $\begin{array}{l}\text { The extension of tax deadlines offered by the government is helping } \\
\text { my business survive the pandemic }\end{array}$ & 3.62 & .715 \\
\hline 6 & $\begin{array}{l}\text { The government and EU-backed liquidity lines and loans for SMEs } \\
\text { are helping my business survive the pandemic }\end{array}$ & 4.23 & .216 \\
\hline 7 & $\begin{array}{l}\text { The "Business Marketplace CoVID-19" has proven to be very useful } \\
\text { for the survival of my business }\end{array}$ & 2.52 & .498 \\
\hline 8 & $\begin{array}{l}\text { In my opinion, the government aid measures are too restrictive (not } \\
\text { enough companies can benefit from them) }\end{array}$ & 2.95 & .501 \\
\hline
\end{tabular}

Source: authors' processing

The first question, related to the respondents' perception regarding the harshness of the government restriction registered a mean value of 2.42 ( $\mathrm{SD}=.512$ ), situating the average answer closer to the disagreement zone than the average zone, which means that our respondents don't consider the government's restrictions to be particularly harsh. This is a very interesting finding, considering that most of our respondents' business have been affected in some way by the government restrictions (as seen in Table 3). This result leads to believe that the Catalan government managed to successfully communicate the reasons behind the restrictions and how these restrictions are helping mitigate the public safety damage that the pandemic is causing, and the SME business owners understood the necessity of these measures, despite greatly hindering their operations.

The second question registered a mean answer of 4.12 (SD=.576), which places in the interval between agreement and strong agreement, which means, on an average, the Catalan SME owner-managers have encountered a severe decline in the demand for their products and services. This could be explained through the fact that Catalonia's (and in a greater extent, the region's largest city of Barcelona) 
dependency on tourism has been the most affected sector during this pandemic. Moreover, $45 \%$ of our respondents own and manage businesses in the hospitality industry and tourists represented a significant proportion of their customers.

The next question has a mean answer of 3.11 ( $S D=.663$ ), placing it in the interval between the neutral and the agreement zone. This value indicates that our respondents had been forced, in some measure, to increase their prices in order to compensate for the lack of demand. A lack of demand means lower revenues, making it harder for the SME to reach a satisfactory level of profitability, or in some cases, even the break-even point.

The mean of 3.49 ( $\mathrm{SD}=.457)$ is one of the highest in our study, placing it in the middle of the interval between neutral and agreement. This shows us that most of our respondents had to temporarily layoff some of their employees, as a solution to having their operating capacity reduced and the demand for their products and services in the lowest point of the last years. This finding is supported by Catalan News report that over 660.000 workers from over 90.000 enterprises (most of them SMEs) submitted temporarily layoff requests.

The fifth question has a mean answer of 3.62 ( $\mathrm{SD}=.715)$, which situates in the interval between the neutral and agreement zone, which means that our respondents have benefited from the extension on tax deadline provided by the Catalan government and this measure has been beneficial for them.

The sixth question registered the highest mean answer of all 8 questions, 4.23 $(\mathrm{SD}=.216)$, which means that the various liquidity lines and government or EUbacked loans have had a significant positive impact upon our respondents' business. This is normal, since most of our respondents' businesses have had their operational capacity reduced and/or have seen the demand for their products/services diminish and these government aid measures provided the much-needed liquidity that they needed in order to survive.

The second to last question had a mean answer of 2.52 (SD=.498) which places it between the disagreement and the neutral zone. This question has the lowest mean score of the four questions regarding the government aid measures, which means the "Business Marketplace COVID-19" is not seen as a very helpful measure by our respondents. This is somewhat to be expected considering our hospitality and services dominated sample, since this measure is targeted more towards healthcare and technology companies which can bring their contribution to the fight against the COVID-19 pandemic.

The last question asked our respondents about their general perception regarding the inclusiveness of the Catalan government aid measures and it registered a mean answer of 2.95 (SD=.501), which places it extremely close to the neutral zone (3). This means that our respondents' perceptions were mixed, and we cannot safely say if the Catalan government aid measures were either inclusive or not inclusive enough.

\section{Conclusions}

This study's aim was to analyse the dominant leadership styles of SME ownermanagers from Catalonia, Spain, as well as how these styles are influenced by different factors, such as Hofstede's cultural dimensions, the company's maturity level and the respondents' gender, and at the same time, to analyse the impact of the COVID-19 upon the Catalan SME environment and the respondents' perception regarding the aid measures implemented by the Catalan government in order to support the business environment during the pandemic.

Our findings have shown that in our sample, most of our respondents practiced a democratic/transformational leadership style. This result was further examined through Hofstede cultural dimensions and was supported by two of the six dimensions (Collectivism and Femininity). 
Moreover, our research has found that the SME owner-managers' leadership style is influenced (among our sample) by the maturity level of his company. Thus, younger companies tend to entice a more autocratical/transactional approach from their leaders, while companies being in the growth and development stage are led by democratic/transformational leaders and older and more mature companies can be efficiently run by laissez-faire/liberal leaders.

Regarding the influence of the respondents' gender upon their dominant leadership style, our findings have shown that in case of both male and female leaders, the dominant style is democratic/transactional, but we can see a larger proportion of male leaders who employ an autocratic/transactional approach compared to female respondents.

In the last part of our research, we have analysed how the COVID-19 pandemic affected the operational capacity of our respondents. Our results have shown us that most of our respondents had to reduce the operations of their business to some degree, $18 \%$ of them not being operational at the moment of this study. Moreover, our findings suggest that our respondents don't consider the government restrictions as being too harsh, the demand for their products and services had been significantly reduced during the pandemic, some of them had to increase the price of their products or services in order to compensate for the lack of demand and many of them had to temporarily lay off a significant part of their staff. Regarding the aid measures implemented by the Catalan government in order to support the business environment, our respondents considered the extension of tax deadlines and the liquidity lines as very useful, unlike the "Business Marketplace COVID-19" which was not seen as extremely helpful, while the overall feeling of the degree of inclusion of the aid measures was mixed.

Regarding the limitations of this study, we should mention that it was conducted in an empirical and quantitative way, the authors having neither the time nor the resources to conduct more complex scientific research. Moreover, the research was conducted online because the authors could not travel to Spain because of the COVID-19 travel restrictions and the sample was chosen arbitrarily. At the same time, the leadership styles were identified based on the respondents' answers to several questions and, thus, might be affected by their subjectivity.

As we have mentioned before, this study is a continuation of the authors' previous doctoral research on leadership styles, which was conducted on a sample of Romanian and Dutch entrepreneurs. We want to further this research by comparing the findings from Romania, the Netherlands, and studying the similarities and the differences between the results, using Hofstede's cultural dimensions.

\section{Acknowledgement}

This work was supported by the grant POCU380/6/13/123990, co-financed by the European Social Fund within the Sectorial Operational Program Human Capital $2014-2020$.

\section{References}

- Alonso-Almeida, M., Perramon, J. and Bagur-Femenias, L. (2017). Leadership styles and corporate social responsibility management: Analysis from a gender perspective. Business Ethics: A European Review. 26, 147-161.

- Andersen, J. A.; Hansson, P. H. (2011). "At the end of the road? On differences between women and men in leadership behaviour". Leadership and Organization Development Journal. 32 (5): 428-441

- Arbaiza, L., Guillen, J. (2016). Subordinate responses to leadership: Evidence from an emerging market firm. International Journal of Organizational Leadership, 5, 433-442.

- Arverson, P., Rohm, H., Wilsey, D., Perry, G., Halbach, L., \& DeCarlo, J. (2010). The Strategic

- Management Maturity Model. Cary, NC: The Balanced Scorecard Institute. 
Retrieved on 10th of October 2020 from http://www.balancedscorecard.org/P ortals/0/PDF/BSCIStrategicManageme ntMaturityModel.pdf

- Avolio. B.J. (1999). Full Leadership Development: Building the Vital Forces in Organizations. Thousand Oaks, CA: Sage.

- $\quad$ Askehave, I., \& Zethsen, K. K. (2014). Gendered constructions of leadership in Danish job advertisements. Gender, Work and Organization, 21(6), 531545.

- Chaganti, R., Cook, R., și Smelts, W. (2002). Effects of styles, strategies and systems on the growth of small businesses. Journal of Development Entrepreneurship, 7(2), 175-192.

- Badea, E. (2017). Antreprenoriatul feminin, potențial sub-utilizat de creștere economică. Available at: $<$ https://valoria.ro/blog/antreprenori atul-feminin-potential-sub-utilizat-decrestere-economica/> [Accessed 9 October 2020].

- Banks, G. C., McCauley, K. D., Gardner, W. L., and Guler, C. E. (2016). A metaanalytic review of authentic and transformational leadership: A test for redundancy. The Leadership Quarterly, 27, 634-652.

- Bass, B. (2008). Bass \& Stogdill's Handbook of Leadership: Theory, Research \& Managerial Applications (4th ed.). New York, NY: The Free Press. pp. 50,623 .

- Bass, B. (1990). Handbook ofleadership: Theory, research, și managerial applications (Third Edition). New York: The Free Press.

- Bennis, W. (2007). The challenges of leadership in the modern world: Introduction to the special issue. American Psychologist, 62(1), 2-5.

- Burlea-Schiopoiu, A. (2009). Success Factors for an Information Systems Projects Team: Creating New Context, Innovation and Knowledge Management in Twin Track Economies: Challenges \& Solutions, vol. 1-3, pp. 936-941.

- $\quad$ Burlea-Schiopoiu, A., Mihai, L.S. (2019). An Integrated Framework on the Sustainability of SMEs. Sustainability, 11(21),
6026; https://doi.org/10.3390/su112 $\underline{16026}$

- $\quad$ Burlea-Schiopoiu, A., Idowu O.S. (2016). The independence of the managers: an ethical dilemma, International Journal of Social Entrepreneurship and Innovation, 4(2), pp. 152-171.

- Burlea-Schiopoiu, A., Idowu, S., Vertigas, St. (2017). Corporate Social Responsibility in Times of Crisis: A Summary, Springer

- $\quad$ Burlea Schiopoiu, A., Rainey, S. (2013). Servant leader/ Servant leadership. In S. Idowu (Ed.), Encyclopedia of Corporate Social Responsibility. Berlin: Springer-Verlag.

- $\quad$ Burlea-Schiopoiu, A., Remme J. (2017). The Dangers of Dispersal of Responsibilities. Amfiteatru Economic, 19(45), pp. 464-476

- Burns, J. (1978). Leadership. New York, NY: Harper și Row.

- Clark, R. A., Hartline, M. D., \& Jones, K. C. (2009). The effects of leadership style on hotel employees' commitment to service quality. Cornell Hospitality Quarterly, 50(2), 209-231.

- Cliff, J. E. (2005). Walking the Talk? Gendered Rhetoric vs. Action in Small Firms. Organization Studies. 26: 63-91.

- Dobbins, Gregory; Platz, Stephanie (1986). Sex Differences in Leadership: How Real Are They?. Academy of Management Review. 11 (1): 118-27

- Eagly, A. \& Carli, L. (2007). Through the labyrinth: the truth about how women become leaders. Boston, MA: Harvard Business School Press

- Erkutlu, H. (2008). The impact of transformational leadership on organizational and leadership effectiveness: The Turkish case. Journal of Management Development, 27(7), 708-726.

- $\quad$ Forsyth, D. (2010). Group Dynamics (5th ed.). USA: Wadsworth.

- Garcia Solarte, M., Garcia-Perez-deLema, D. and Madrid-Guijarro, A. (2018). Gender diversity and its impact on high-tech SMEs organizational leadership. Gender in Management. 33(6). 499-523

- Gordon, A., Yukl, G. (2004). The future of leadership research: Challenges and opportunities. German Journal of 
Human Resource Management, 18(3), 359-365.

- Hamori-Ota, V. E. (2007) Gender differences in leadership style: Predictors of level of agreement between leader self-ratings and supervisory ratings, peer ratings, and ratings by direct reports. University of Michigan

- Hargis, M.B.; Wyatt, J.D. and Piotrowski, C. (2011). Developing Leaders: Examining the Role of Transactional and Transformational Leadership Across Contexts Business. Organization Development Journal. 29 (3), 51-66.

- Hartline, D., Wooldridge, B., \& Jones, K. (2003). Guest perceptions of hotel quality: Determining which group count most. Cornell Hotel \& Restaurant Administration Quarterly, 44, 43-52.

- Hussain, M., Hassan, H. (2016). The leadership styles dilemma in the business world. International Journal of Organizational Leadership, 5, 411-425.

- Judge, T. A., \& Piccolo, R. F. (2004). Transformational and transactional leadership: A meta- analytic test of their relative validity. Journal of Applied Psychology, 89, 755-768.

- $\quad$ Kent, T. W.; Schuele, U. (2010). Gender Differences and Transformational Leadership Behavior: Do Both German Men and Women Lead in the Same Way? International Journal of Leadership Studies. 6 (1): 52-66.

- Krieger, M. (2001). Sociología de las organizaciones. Una introducción al comportamiento organizacional". Mexico: Prentice Hall.

- Levy, P. (2010). Industrial organizational psychology: Understanding the workplace (3rd ed.). New York: NY: Worth Publishers

- Management Research Group (2013). The Glass Ceiling Revisited: Gender and Perceptions of Competency

- Mendez, R., Vera Munoz, J., și Vera Munoz, M. (2013). Leadership styles and organizational effectiveness in small construction businesses in Puebla, Mexico. Global Journal of Business Research, 7(5), 47-56

- Mihai, L. (2015a). The particularities of leadership styles in Romanian Organisations. 11th European Conference on Management, Leadership and Governance (pg. 580-587). London: Academic Conferences and Publishing International.

- Mihai, L. (2016b). The particularities of leadership styles among dutch small and medium business owners. Annals of the 'Constantin Brâncuşi' University of Târgu Jiu, Economy Series, 6, 240-248

- Mihai, L. (2018). Impactul stilurilor de leadership asupra performantelor interprinderilor mici si mijlocii. Craiova, Romania: Editura Universitaria.

- Mihai, L.S., Burlea-Schiopoiu, A., Mihai M. (2017). Comparison of the leadership styles practiced by Romanian and Dutch SME owners, International Journal of Organizational Leadership, 6(1): 4-16.

- Moritz, R. (2011). SME in the Netherlands. Frankfurt am Main: Deutsche Bank Research.

- Noguera, M. (2012). Female entrepreneurship in Catalonia: An institutional approach. Doctoral thesis, Universitat Autonoma de Barcelona.

- $\quad$ Patiar, A., Mia, L. (2008). The interactive effect of market competition and use of MAS information on performance: Evidence from the upscale hotels. Journal of Hospitality and Tourism Research, 32(2), 209-234.

- Peris-Ortiz, M., Willoughby, M. and Rueda-Armengot, C. (2012). Performance in franchising: the effects of different management styles. The service Industries Journal. 32(16), 25072525.

- Quintana, T.A., Park S. and Araujo Cabrera, Y (2015). Assesing the effects of leadership styles on employees' otucomes in international luxury hotels. Journal of Business Ethics. 129, 469-489

- Ricard, L.M, Klikn, E.H, Lewis, M. and Ysa, T. (2017). Assessing public leadership styles for innovation: a comparison of Copenhagen, Rotterdam and Barcelona. Public Management Review, 19(2), 134-156

- Rotaru, V., Mihai, M. and Ogarca, R. (2020). Succesion Management in Romanian SMEs. Revista ManagementMarketing Craiova, XVII(2), to be published.

- Rowe, W. G., Cannella, A., Rankin, D., Gorman, D. (2005). Leader succession 
and organizational performance: Integratingthe common-sense, ritual scapegoating, and vicious-circle succession theories. The Leadership Quarterly, 16(2), 197-219.

- European Comission (2019). SBA Fact sheet-Spain.

- $\quad$ Salamzadeh, Y and Hajiseydjavadi, S.P. (2016). Analyzing correlation of leadership style with organisational maturity, A military organisation: A case Study. International Journal of Business and Management Invention (IJBMI), 5(10). Retrieved on the 10th of October from https://www.ijbmi.org/papers/Vol(5) 10/version-3/J0510085101.pdf

- Stogdill, R. M. (1974). Handbook of leadership: A survey of theory and research. New York: Free Press.

- Tintore, M. (2019). Introducing a model of transformational prosocial leadership. Journal of Leadership Studies. 13(3), 15-34.

- Trinidad, C. \&Normore, A .H. (2005). Leadership and gender: A dangerous liaison? Leadership\&Organisation Development Journal, 26 (7/8), 574-590

- Van Wart, M. 2012. Leadership in Public Organizations; Man Introduction. New York: M.E. Sharpe.

- Aid for productive activity and employment due to the effects of coronavirus, Retrieved on the 10th of October 2020 from http://catalonia.com/.content/docume nts/2020/aid-productive-activityemployment-coronavirus.pdf.

- $\quad$ ANALYSIS: Why Barcelona will have to change to survive impact of pandemic, retrieved on the 10th of October from https://www.thelocal.es/20200806/a nalysis-barceolan-coronaviruseconomy-what-does-the-future-holdfor-barcelona-without-tourists

- Catalan SMEs grow in number and production in 2017, Retrieved on the 10th of October 2020 from https://www.catalannews.com/busines s/item/catalan-smes-grow-in-numberand-production-in-2017
- Catalonia closes bars, restaurants, and shopping centres due to coronavirus, Retrieved on the 10th of October 2020 from

https://www.elnacional.cat/en/news/c oronavirus-catalonia-bars-restaurantsclose 479721_102.html.

- Hofstede cultural dimensions for Spain, Retrieved on the 10th of October 2020 from https://www.hofstedeinsights.com/countrycomparison/spain/

- Leadership Styles Questionnaire, Retrieved on the 15th of March, 2020 from

http://www.sagepub.com/northouseint ro2e/study/resources/questionnaires/8 9527_03q.pdf

- Leadership Styles Survey, Retrieved on the 15th of March, 2020 from http://www.nwlink.com/ donclark/lea der/survstyl.html

- Measures for the new normality, Retrieved on the 10th of October 2020 from https://www.barcelona.cat/covid19/en Llockdown-exit-strategy-city

- PIB de las Comunidades Autónomas, Retrieved on the 10th of October 2020 from https://datosmacro.expansion.com/pi b/espana-comunidades-autonomas

- Regional Innovation Monitor Plus, Retrieved on the 10th of October 2020 from https://ec.europa.eu/growth/toolsdatabases/regional-innovationmonitor/base-profile/catalonia

- Spain No of Companies: Catalonia, Retrieved on the 10th of October 2020 from

https://www.ceicdata.com/en/spain/ number-of-companies-by-region/noof-companies-catalonia,

- The Strategic Management Maturity Model, retrieved on the 10th of October 2020 from https://strategymanage.com/resource s/strategic-planning-basics/strategicmanagement-maturity-model/ 